\title{
The Impact of Clinical Trials on the Use of Medications for Acute Myocardial Infarction
}

\section{Citation}

Col, Nananda F. 1996. "The Impact of Clinical Trials on the Use of Medications for Acute Myocardial Infarction." Archives of Internal Medicine 156 (1) (January 8): 54. doi:10.1001/ archinte.1996.00440010066009.

\section{Published Version}

doi:10.1001/archinte.1996.00440010066009

\section{Permanent link}

http://nrs.harvard.edu/urn-3:HUL.InstRepos:32692617

\section{Terms of Use}

This article was downloaded from Harvard University's DASH repository, and is made available under the terms and conditions applicable to Other Posted Material, as set forth at http:// nrs.harvard.edu/urn-3:HUL.InstRepos:dash.current.terms-of-use\#LAA

\section{Share Your Story}

The Harvard community has made this article openly available.

Please share how this access benefits you. Submit a story.

\section{Accessibility}




\title{
The Impact of Clinical Trials on the Use of Medications for Acute Myocardial Infarction
}

\author{
Results of a Community-Based Study
}

Nananda F. Col, MD, MPP, MPH; Thomas J. McLaughlin, ScD; Stephen B. Soumerai, ScD; David W. Hosmer, Jr, PhD; Jorge Yarzebski, MD, MPH; Jerry H. Gurwitz, MD; Joel M. Gore, MD; Robert J. Goldberg, PhD

Baekgrounds The impact of clinical trials on medical practice remains controversial, in part because of weak study designs and nonrepresentative study samples.

Objoctive: To assess changes in trends in medication use in the setting of acute myocardial infarction (AMI) before and after publication of two large clinical trials: the Second International Study of Infarct Survival (ISIS-2) trial that supported the use of aspirin after AMI and the Multicenter Diltiazem Postinfarction Trial that reported no overall benefit from the use of calcium antagonists after AMI.

\footnotetext{
Mothodss Study patients consisted of 2114 patients hospitalized with AMI in 16 hospitals in metropolitan Worcester, Mass, during 1986, 1988, and 1990. Data were obtained from medical records. We used multivariable logistic regression models to examine the rate of change in the use of selected medications before and after trial publication, controlling for medical history, characteristics and complications of AMI, medications taken, and procedures performed during hospitalization. The dependent variable was receipt of the specific medication under investigation.
}

Resulhs: Before publication of ISIS-2, 26\% of patients with AMI received aspirin while hospitalized compared with $66 \%$ after its publication. However, in-hospital aspirin use began to rise before ISIS- 2 with an immediate increase in the level of use occurring after trial publication but with no significant change in the rate of increase. Before publication of the Multicenter Diltiazem Postinfarction Trial, 57\% of patients with AMI were new recipients of calcium antagonists compared with $51 \%$ after trial publication. The decrease in calcium antagonist use began after trial publication (odds ratio, 0.79 per 6-month period; $95 \%$ confidence interval, 0.71 to 0.88 ).

Conclusions: The published results of large trials of cardiovascular therapies have had variable impact on medication use. Efforts to assess the effects of publication of new scientific information on medical care need to consider prior trends in treatment patterns and the varying contexts of medical care. They should consider both direct and indirect routes of influence.

(Arch Intern Med. 1996;156:54-60)
From the Departments of Medicine and Family and Community Medicine (Drs Col, Yarzebski, Gore, and Goldberg), University of Massachusetts Medical School, Worcester; Department of Ambulatory Care and Prevention, Harvard Medical School and Harvard Community Health Plan (Drs McLaughlin and Soumerai), Boston Mass; University of Massachusetts School of Public Health, Amherst (Dr Hosmer); and the Gerontology Division, Department of Medicine, Brigham and Women's Hospital, Boston (Dr Gurwitz) $\mathrm{Dr}$ Col is now with the New England Medical Center, Boston.

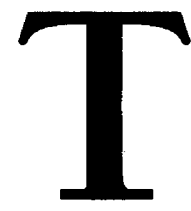

HE RATE at which new scientific evidence on the efficacy of medical technologies influences clinical practice has important consequences on the quality of medical care. The randomized controlled trial (RCT) represents the principal means for evaluating the efficacy of therapeutic agents. While several studies have attempted to evaluate the direct impact of RCTs on clinical practice, ${ }^{1-3}$ divergent results have been observed. One review ${ }^{4}$ of the published literature found that only two of 25 studies reviewed were able to demonstrate a detectable change in clinical practice based on publication of the results of an RCT. ${ }^{5,6}$

A recent study found the publication of large RCTs on the treatment of acute myocardial infarction (AMI) to be associated with measurable changes in clinical practice. ${ }^{7}$ However, this study was performed within the context of a large RCT (the Survival and Ventricular Enlargement [SAVE] Trial ${ }^{8}$ ). The study subjects were a highly select group representing less than $10 \%$ of patients with AMI who met eligibility requirements and had survived the acute hospitalization for at least 72 hours, ${ }^{9}$ thereby raising questions concerning generalizability to broader community settings. In addition, the possibility exists that the observed changes in practice patterns may have begun before the publication of the RCT.

A variety of nonscientific factors can also affect prescribing practices over time. These include pharmaceutical company

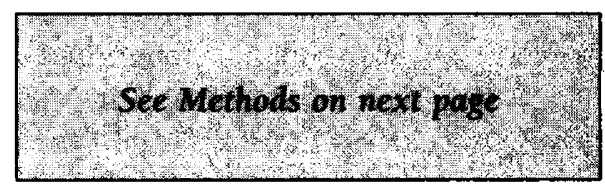




\section{METHODS}

We examined the use of aspirin and calcium antagonists among patients hospitalized with validated AMI. The study population was drawn from the Worcester Heart Attack Study, a population-based investigation examining changes over time in the incidence, case-fatality rates, and treatment patterns for AMl among residents from a defined population setting. ${ }^{18-23}$ The study population, identified by a review of medical records, included all patients hospitalized with a primary or secondary discharge diagnosis of AMI in 16 Worcester, Mass, Standard Metropolitan Statistical Area hospitals during the calendar years 1986, 1988, and 1990. The patients' medical records were individually reviewed and validated for the presence of AMI. The criteria used for the diagnosis of AMI in our study have been described previously ${ }^{18-20}$ and include a clinical history of prolonged chest pain not relieved by rest or use of sublingual nitrates, elevation of the level of serum creatine kinase and its isoenzyme subfraction or of the level of lactate dehydrogenase, and serial electrocardiographic tracings obtained during hospitalization showing ST-segment changes or Q waves or both typical of AMI. At least two criteria were needed to be satisfied for inclusion in the study. The data obtained from the medical record included patient demographic characteristics, medical history, characteristics of the AMI (eg, AMI order, extent, and location), medications taken before and during hospitalization, complications of AMI occurring during the acute hospital admission, specialized procedures performed during hospitalization, and date of hospitalization. We were not able to obtain data on the prescribing physician. The data on in-hospital medication use were obtained from nurses' notes to ensure that patients actually received the medication in question. Only class-specific data on medication use were obtained for calcium antagonists; we distinguished between newly initiated and continuation of ongoing therapy.

\section{DATA ANALYSIS}

Differences in selected continuous or categorical data were assessed by Student's $t$ tests and the $\chi^{2}$ tests of statistical significance, respectively. The Cochran-Mantel-Haentzel $\chi^{2}$ test was used to assess the significance of any observed trends in drug use or baseline characteristics over the period under study; all $P$ values were two tailed. The impact of specific published RCTs on medication use was assessed using multivariable logistic regression models to test the association between medication use and date of hospital admission; the dependent variable examined in these analyses was receipt of the specific medication under investigation. Initial analyses were similar to those performed in a recent analysis ${ }^{8}$ and did not account for preexisting time trends in medication use; the date of hospital admission was characterized as a dichotomous variable occurring either before or after publication of the relevant RCT. A second set of analyses accounted for any changes in practice patterns occurring before publication of the RCT. By incorporating variables that capture changes in medication use before and after publication of RCT results, these models enabled us to examine both the immediate trial effect and monthly changes following the publication of trial results compared with pretrial publication. Similar types of modeling approaches have been previously used to assess the impact of policy changes on drug use, using linear regression models. ${ }^{24,25}$ To adjust for potential confounders at the individual patient level, these linear modeling techniques were modified to multivariable logistic regression models. ${ }^{26}$ These models included a linear term for hospitalization month (representing the monthly rate of change in the log odds ratio [OR] for receipt of the medication before trial publication), a dichotomous term for admission before or after publication of the RCT (representing the level of change occurring immediately after publication of the RCT), as well as an interaction term representing the change in slope occurring after trial publication. The immediate trial effect compares drug use in the month after trial publication with that in the month preceding publication, incorporating both slope and level change variables. The month in which the trial was published was split on the day of publication into prepublication vs postpublication periods. Variables that changed significantly over the period under investigation or that were associated with medication use in univariate analyses were included in these models to give as complete control for confounding as possible. Models examining in-hospital aspirin use included the following: patient age, gender, and type of insurance coverage; hospital size (based on the number of patients with AMI treated per year); history of angina, congestive heart failure, or diabetes; complications of AMI (recurrent angina, cardiac arrest, congestive heart failure, or pulmonary edema, or ventricular tachycardia); procedures performed during hospitalization (percutaneous transluminal coronary angioplasty and coronary artery bypass graft); and receipt of thrombolytic therapy. The models examining the impact of RCTs on calcium antagonist use additionally included: history of AMI; characteristics of AMI (infarct size as determined by peak creatine kinase findings, $Q$ wave or non- $Q$ wave, and inferior and/or posterior vs anterior AMI), and complications of AMI (cardiogenic shock, extension of AMI, ventricular fibrillation, and thirddegree heart block). We controlled for within-hospital correlation in the logistic regression models using previously described methods. ${ }^{27-29}$

Recognizing that publicity was generated during the course of these trials and that results were reported at a large conference several months before their publication in a peerreviewed journal, ${ }^{30}$ logistic regression models were repeated using the conference reporting date as the cutoff time.

To determine the relative influence of RCTs in a primarily community setting vs a primarily academic setting, we compared patterns of drug use over time for patients in the community-based Worcester Heart Attack Study with patients enrolled in a large RCT (the SAVE Trial ${ }^{8}$ ). Because the academic status of several of the participating Worcester hospitals changed during the study period examined, we were not able to consistently distinguish between teaching and nonteaching hospitals in this study population.

Continued on next page 
The clinical trials selected for evaluation in this study were the same as those included in a recently published trial $^{8}$ describing the impact of RCTs on clinical practice, thus enabling a comparison between community and academic settings. Three large RCTs published in wellrespected, peer-reviewed journals that had clear implications for clinical practice were chosen: (1) the Second International Study of Infarct Survival (ISIS-2) trial, ${ }^{31,32}$ published August 13, 1988, found improved survival 5 weeks after AMI among patients treated with aspirin compared with placebo; (2) the Multicenter Diltiazem Postinfarction Trial (MDPT), ${ }^{33}$ and the Secondary Prevention Reinfarction Israeli Nifedipine Trial (SPRINT), ${ }^{34}$ published in August 1988, reported no overall survival benefit from the use of calcium antagonists after AMI. Both the ISIS-2 and MDPT results were reported before publication at the American College of Cardiology meeting on March 31, $1988 .^{35,36}$

promotions and introduction of new products to the marketplace $^{10,11}$; government regulations and reimbursement restrictions ${ }^{12,13}$; media reports ${ }^{14}$; and formal and informal peer influence through specialty organizations and opinion leaders. ${ }^{15}$ Even though these factors may be indirectly affected by published RCTs, they are likely to represent stronger influences on prescribing practices in community settings than publication of RCTs alone. ${ }^{16}$ The failure to control for preexisting trends in prescribing caused by such nonscientific factors has been shown to produce spurious and often inflated estimates of the effects of educational interventions on prescribing patterns. ${ }^{16,17}$

The purpose of our study is to assess the impact of large published RCTs of cardiovascular medications on clinical practice from a community-wide perspective and to examine whether controlling for prepublication trends in medication use affects the conclusions drawn.

\section{RISIIIS}

A total of 2114 patients in the Worcester area had a validated AMI during 1986, 1988, and 1990. The median age of the patient population was 68 years; $61 \%$ were men. The patient characteristics and use of drugs and procedures were generally stable over time (Tablo I), except for an increase in the use of thrombolytic agents.

\section{ASPIRIN USE DURING HOSPITALIZATION}

Forty-four percent of all study patients received aspirin during their hospitalization for AMI. The percentage of patients receiving aspirin increased from $19 \%$ in the first half of 1986 to $75 \%$ during the last half of 1990 . Before the publication of ISIS-2, $26 \%$ of patients with AMI received aspirin compared with $66 \%$ subsequent to its pub-

\begin{tabular}{|c|c|c|c|c|}
\hline Gharactedstis ist: & $(n=784)$ & 1998 & $\begin{array}{r}1090 \\
(n-738)\end{array}$ & Pf \\
\hline \multicolumn{5}{|l|}{$\begin{array}{l}\text { Demographic and hospital } \\
\text { characteristics }\end{array}$} \\
\hline Median age, y & 69.0 & 69.0 & 70.5 & 04 \\
\hline Male & 59.5 & 60.4 & 61.7 & NS \\
\hline Length of stay, median & 10.0 & 9.5 & 9.0 & .04 \\
\hline \multicolumn{5}{|l|}{ Medical history } \\
\hline Diabotes & 26.2 & 24.5 & 26.9 & NS \\
\hline Angina & 25.3 & 27.5 & 287 & Ns \\
\hline Hypertension & 48.5 & 48.9 & 52.2 & is \\
\hline Congestlve heart failure & 15.7 & 10.6 & 16.6 & 003 \\
\hline AWI & 30.8 & 32.6 & 35.2 & NS \\
\hline Stroke & 8.2 & 9.8 & 8.8 & NS \\
\hline \multicolumn{5}{|l|}{ AMI characteristics } \\
\hline Qwave AMI & 52.9 & 46.4 & 46.9 & 08 \\
\hline Aneria AWI & 52.9 & 419 & 46,2 & $<, 001$ \\
\hline \multicolumn{5}{|l|}{ Complications of AMI } \\
\hline \multicolumn{5}{|l|}{ Third degree arteriovenous } \\
\hline block & 6.1 & 7.5 & 4.1 & 08 \\
\hline Atral fibrilation & 17.6 & 17.7 & 20.7 & NS \\
\hline Cardiogonic shock & 7.8 & 9.2 & 49 & 007 \\
\hline Ventricular fibrillation & 8.9 & 7.1 & 6.5 & NS? \\
\hline Rocurrent angina & 42.1 & 29.4 & 43.9 & $<001$ \\
\hline \multicolumn{5}{|l|}{ Hospital procedues } \\
\hline Coronary anoioplasty & 20 & 3.0 & 2.7 & NS \\
\hline Corenary artery bypass graft & 1.1 & 3.0 & 1.5 & 03 \\
\hline $\begin{array}{l}\text { Rocejpt of thrombolytic } \\
\text { agents }\end{array}$ & 9.5 & 20.3 & 24.2 & $<001$ \\
\hline
\end{tabular}

* Values are given as percents. AMI indicates acute myocardial infarction; $N S$, not significant.

$t x^{2}$ for trend.

lication. Using multivariable logistic regression models that did not account for time trends occurring before trial publication, patients hospitalized after publication of ISIS-2 were significantly more likely to be treated with aspirin than those hospitalized before its publication (adjusted OR, 6.6; 95\% confidence interval [CI], 5.3 to 8.2). However, the trend toward increased use of aspirin after infarction began before publication of ISIS-2. During the period before publication of this trial, aspirin use increased from $20 \%$ (first quarter, 1986) to $37 \%$ (third quarter, 1988) $(P<.001$; unadjusted OR, 1.26 per 6-month period; $95 \% \mathrm{CI}, 1.18$ to 1.36 ) (Figure 1).

When multivariable regression models were repeated controlling for time trends in aspirin use before trial publication, the OR for receipt of aspirin increased significantly before trial publication (adjusted OR, 1.24 per 6 -month period; $95 \% \mathrm{CI}, 1.15$ to 1.34) (Table 2). After publication of ISIS-2 there was an immediate increase in aspirin use (adjusted OR, $1.77 ; 95 \% \mathrm{CI}, 1.19$ to 2.65 ). The posttrial publication trend continued to increase at the same rate as during the prepublication period. Using multivariable logistic regression models that accounted for within hospital correlation of medication use, ${ }^{27-29}$ similar results were obtained.

When these regression models were repeated (controlling for time trends) using the conference reporting date instead of publication date as the critical threshold, 


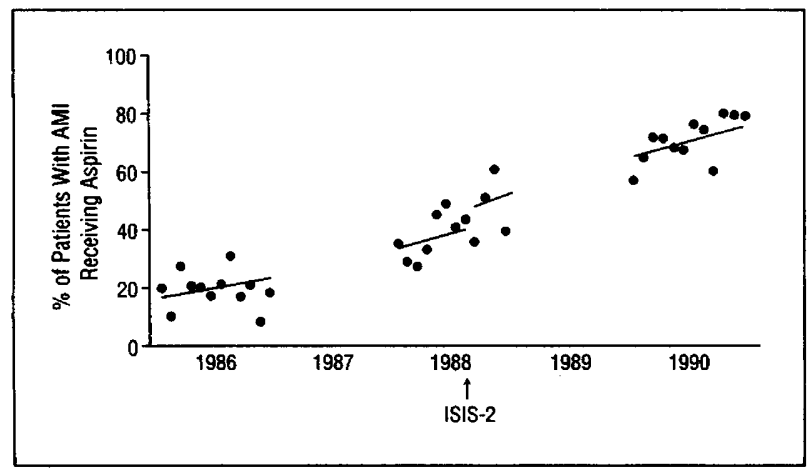

Figure 1. Aspirin use after acute myocardial infarction (AMI) according to date of hospitalization. Each solid circle indicates the percentage of all patients with AMI receiving aspirin for each 1-month period; lines, fitted, unadjusted regression lines before and after trial publication; and ISIS-2, the second international Study of infarct Survival.

the adjusted OR for receipt of aspirin before the conference reporting date was 1.13 per 6 -month period $(95 \%$ $\mathrm{CI}, 1.00$ to 1.28 ). After the time of the conference report, this adjusted OR increased to 1.37 per 6-month period ( $95 \% \mathrm{CI}, 1.27$ to 1.47 ). An immediate increase in aspirin use occurred during the month after the results of this trial were reported (adjusted OR, $4.17 ; 95 \% \mathrm{CI}$, 1.68 to 10.37 ).

\section{USE OF CALCIUM ANTAGONISTS}

Before publication of the MDPT and SPRINT trials, $57 \%$ of patients with AMI received calcium antagonists while hospitalized, decreasing to $51 \%$ subsequent to publication. A greater change was seen among patients newly receiving calcium antagonists. Before trial publication, $43 \%$ of patients were new recipients of calcium antagonists, decreasing to $24 \%$ during the latter half of 1990 (Figure 2).

Using multivariable logistic regression models that did not account for time trends occurring before publication, patients hospitalized after trial publication were significantly less likely to be newly receiving calcium antagonists than those hospitalized before trial publication (adjusted OR, $0.59 ; 95 \% \mathrm{CI}, 0.49$ to 0.71 ). When these regression analyses were repeated controlling for changes in calcium antagonist use over time, no significant time trend in the new initiation of calcium antagonists was observed before trial publication (adjusted OR, 1.04 per 6-month period; $95 \% \mathrm{CI}, 0.97$ to 1.11 ). Although no immediate trial effect was observed, a significant trend toward decreased use was observed after publication (adjusted OR, 0.79; 95\% CI, 0.71 to 0.88 ) (Table 2).

Similar results were found when examining all inhospital use of calcium antagonists (ie, new and continuing therapy) (Table 2 and Figure 3 ). When using multivariable logistic regression models accounting for within-hospital correlation of medication use $e^{27-29}$ the findings were similar to the reported results.

When models were repeated using the date of conference reporting as the threshold instead of trial publication date, similar results were obtained. The adjusted OR for new receipt of calcium channel blockers before the conference reporting date was 1.07 per 6-month pe- riod ( $95 \% \mathrm{CI}, 0.96$ to 1.19 ). After the time of the conference report, this adjusted OR decreased to 0.81 per 6-month period ( $95 \% \mathrm{CI}, 0.76$ to 0.87 ). An immediate decrease in new calcium channel blocker use occurred during the month after the results of this trial were reported (adjusted OR, $0.29 ; 95 \% \mathrm{CI}, 0.10$ to 0.61 ).

Because subgroup analyses from the MDPT suggested that patients with non-Q-wave AMI might selectively benefit from the administration of calcium antagonists in the postinfarction period, tests for time trends were repeated while stratifying patients into those with $\mathrm{Q}$-wave vs those with non-Q-wave AMI. Among patients with Q-wave AMIs, no time trends in the new receipt of calcium antagonists were detected before trial publication ( $46 \%$ to $48 \%$ ), whereas use of calcium antagonists decreased substantially after trial publication ( $48 \%$ to $15 \%$, $P=.001$ ). Among patients with non-Q-wave AMIs, no significant change in use occurred either before or after trial publication (before publication, $35 \%$ to $43 \%, P=.06$; after publication, $43 \%$ to $36 \%, P=.08$ ).

\section{DIFFERENCES IN DRUG USE BETWEEN THE COMMUNITY SETTING AND WITHIN THE SAVE TRIAL}

Patterns of drug use observed in the present community setting were compared with those of patients included in the SAVE Trial ${ }^{8}$ during similar time periods before publication or conference reporting of trial results (December 1986 for the community setting compared with January 1987 for SAVE patients), recognizing that patients included in the SAVE Trial were younger and healthier than those in the community setting. In-hospital aspirin use was lower in the community setting (18\% compared with $39 \%$ in the SAVE Trial), whereas baseline calcium antagonist use was comparable in both settings (55\% vs $57 \%$ ). We were able to compare the rates of change in medication use in the community setting with that observed within the SAVE Trial from this period to January 1990 . Aspirin use increased significantly more rapidly in the Worcester community sample than within the SAVE Trial ( $222 \%$ vs $85 \%$ ). The decline in the use of calcium antagonists was lower in the community setting (2\%) during this period than within the SAVE Trial (42\%) despite similar baseline levels of use. At the last point in time for which the two study populations could be compared (January 1990), the use of aspirin was lower in the Worcester community setting (57\%) than within the SAVE Trial $(72 \%)$. The use of calcium antagonists was higher in the community setting than within the SAVE Trial $(55 \%$ vs $33 \%$ ).

\section{( () 1111$)$}

The RCT has become the gold standard for evaluating the efficacy of therapeutic practices. However, such trials require large numbers of patients, involve a long duration of follow-up, and are very costly and logistically difficult to conduct. ${ }^{3}$ The rigid inclusion and exclusion criteria imposed in these trials raise questions concerning the generalizability of the findings to patients treated in community settings. Given these concerns, it is im- 


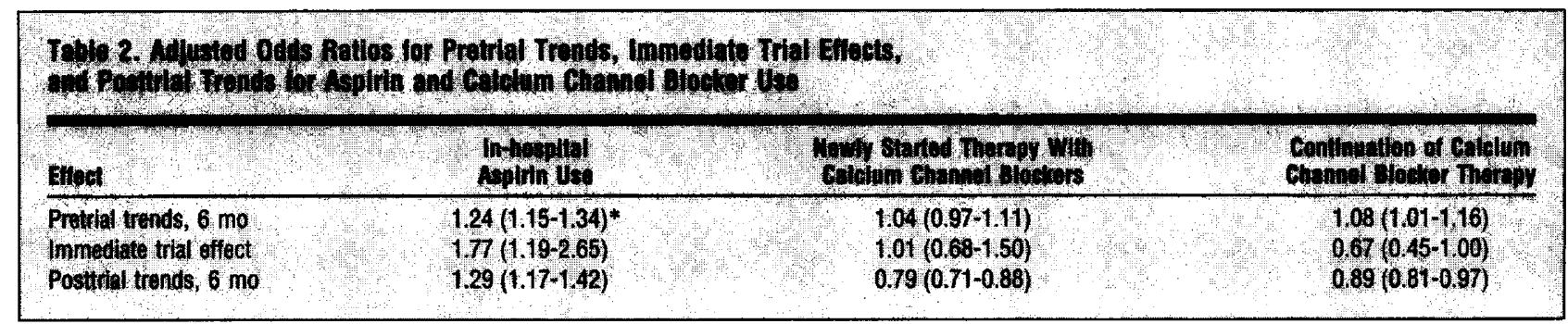

* Numbers within parentheses are $95 \%$ confidence intervals.

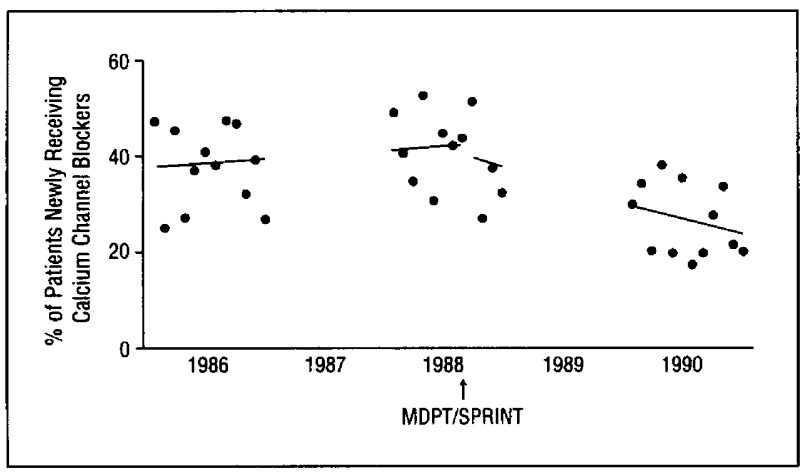

Figure 2. The use of newly initiated calcium antagonists after acute myocardial infarction according to date of hospitalization. Each solid circle indicates the percentage of all patients with acute myocardial infarction receiving newly initiated treatment with calcium antagonists for each 1-month period; lines, fitted, unadjusted regression lines before and after trial publication; MDPT, Multicenter Diltiazem Postinfarction Trial; and SPRINT, Secondary Prevention Reinfarction Israeli Nifedipine Trial.

portant to assess the impact of published RCTs on community medical practice, rather than only within the constructs of more specialized academic medical centers.

Our results were sensitive to the analytic approach used. When using a simple before and after quasiexperimental design similar to methods used in a recent study, ${ }^{8}$ we observed changes in both of the medication categories investigated that suggested a marked effect of RCTs on community practice. However, when trends before publication of the RCT were taken into account in subsequent analyses, a more complex picture emerged. We found publication of ISIS-2 to have a limited impact on in-hospital aspirin use, with only an immediate (ie, 1 month) effect detectable. Reporting of ISIS-2 trial results several months before its publication in a peerreviewed journal appeared to have a greater discernible impact on aspirin use than did its actual publication and may have started the upward trend that was observed. Although a statistically significant decline in the rate of use of calcium channel blockers was observed after publication of the RCT, the magnitude of this change was small.

The main strength of our study is its inclusion of a large number of community patients with validated AMI. The demographic and socioeconomic characteristics of residents in the Worcester metropolitan area are similar to those of the continental United States. The main limitations of our study include the relatively short duration of follow-up time after trial publication, lack of data for the interim years 1987 and 1989 to more systematically examine changes over time in medica-

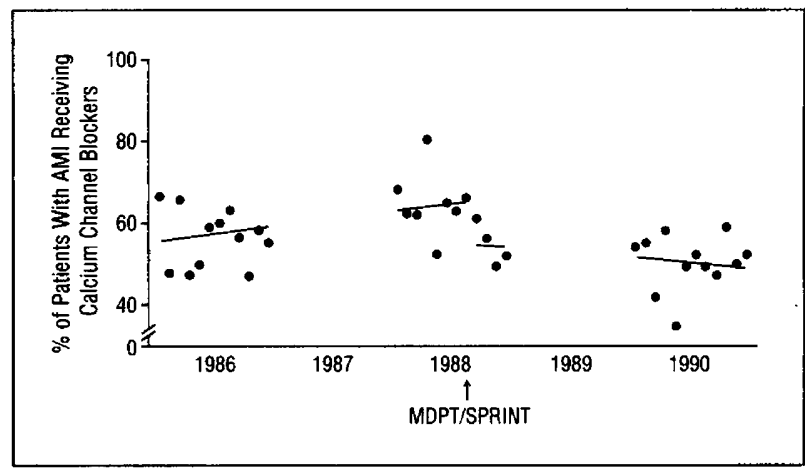

Figure 3. The use of calcium antagonists after acute myocardial infarction (AMI) according to the date of hospitalization. Each solid circle indicates the percentage of all patients with AMI receiving calcium antagonists for each 1-month period; lines, fitted, unadjusted regression lines before and after trial publication; MDPT, Multicenter Diltiazem Postinfarction Trial; and SPRINT, Secondary Prevention Reinfarction Israeli Nifedipine Trial.

tion patterns, and lack of information on the prescribing physicians.

Differences between the results of the present study and those found in the SAVE Trial could reflect real differences in patterns of drug use between the community and academic settings. Alternatively, they may stem from different analytic methods applied in the two studies as well as from differences in measured or unmeasured patient characteristics. Previous studies have demonstrated that research designs failing to control for preintervention trends have produced inflated estimates of the effects of educational and regulatory interventions on prescribing practice. ${ }^{17,18}$ Similarly, the failure to consider trends occurring before the publication of RCTs may have led to an overestimation of the influence of an individual RCT on clinical practice. For example, results published by the SAVE Trial investigators showed that aspirin use after AMI increased from $39 \%$ to nearly $60 \%$ before publication of ISIS-2 (from January 1987 to the first half of 1988), though this increase was not accounted for in subsequent analyses.

Several difficulties arise in trying to determine the impact of publication of an individual RCT on clinical practice. While we focused on the impact of very large RCTs, there were, in fact, numerous ongoing trials endorsing changes in clinical practice, making it difficult to discern the influence of a single study on physicians' practice patterns. Failure to observe a large impact of the publication of the ISIS-2 trial on aspirin use may have been influenced by the prior accumulation of evidence (publication of other trials or meta-analyses) concern- 
ing the efficacy of aspirin in the secondary prevention of cardiovascular-related events. ${ }^{37-43}$ More importantly, some of the increase in aspirin use seen before publication of the ISIS- 2 could be directly related to the trial itself. Since this trial was conducted over several years before publication of its results, publicity generated during its conduct could have affected prescribing patterns. Our study demonstrates the impact that the reporting of results of this trial had on clinical practice.

The differences in patterns of drug use observed between the community setting of our study and within the context of the SAVE Trial may partially be explained by the strict inclusion and exclusion criteria applied to patients within the SAVE Trial. Subjects in an RCT are typically younger and with fewer comorbidities than those studied in the community setting, and they are likely to have fewer contraindications to medication therapy. ${ }^{44}$ This may account for the increased baseline rate of aspirin use observed within the SAVE Trial. Additionally, patients in the SAVE Trial had decreased ejection fractions, making them less likely to receive calcium antagonists. Differences in the characteristics and practice patterns of the physician populations in these two groups may also influence the prescribing patterns observed. Certain physician characteristics (type of practice, board certification, specialization) are likely to influence their knowledge of RCTs and willingness to adopt or abandon clinical practices. ${ }^{45,46}$ More physicians involved in the SAVE Trial may have been specialists, board certified, or engaged in group practice, factors that would presumably increase their familiarity with and rate of adoption of new clinical practices. Furthermore, their involvement in a large RCT might have exposed them to more communication channels than community-based physicians.

When one considers an RCT as an initial step in a complex sequence of events leading to physician awareness, acceptance of trial results, trial of new clinical practices, and adoption of new clinical behaviors, ${ }^{47}$ it may take many years for the full impact of an RCT on clinical practice to be realized. In addition, behavior change may depend on acceptance of the innovation by local opinion leaders ${ }^{48}$ Although we were able to follow practice patterns for up to 2 years after the publication of trial results, a longer follow-up period would have been desirable. A recent study ${ }^{49}$ found a time lag of at least 3 years between the onset of a change in practice and the attainment of a steady state in practice patterns.

While the publication of the results of an RCT may herald changes in clinical practice patterns, changes in practice may precede the demonstration of efficacy by publication of a clinical trial. Our study shows that aspirin use during hospitalization for AMI began to increase after reporting of the ISIS- 2 trial before its publication, with no significant change in the rate of increase occurring after publication. On the other hand, the trend toward a decreasing use of calcium antagonists was temporally associated, albeit small, with the publication of the MDPT and SPRINT trials.

That physicians do not always rely on the results of clinical trials to guide their practice is more understandable when one considers that clinical practice has evolved over the years largely without the benefit of RCTs. One study estimated that RCTs have been applied to only $10 \%$ to $20 \%$ of medical practices. ${ }^{50}$ A study ${ }^{51}$ tracing the introduction of innovative practices in surgery and anesthesia found that only one third of 107 innovations were based on results obtained from clinical trials.

In light of the clear but limited impact of publication of the results of an individual RCT on clinical practice in the community and the tremendous investments required for the successful conduct and completion of a clinical trial, more emphasis should be placed on assessing active dissemination of the results of RCTs to community-based physicians and on identifying and overcoming barriers to the acceptance of new practices that are shown to be efficacious.

\section{Accepted for publication June 7, 1995.}

Reprint requests to the Department of Medicine, University of Massachusetts Medical School, 55 Lake Ave N, Worcester, MA 01655 (Dr Goldberg).

\section{RI I I RI Y I}

1. Chalmers TC. The impact of controlied trials on the practice of medicine. Mt Sinai J Med. 1974;41:753-759.

2. Friedman L, Wenger NK, Knatterud GL. Impact of the coronary drug project findings on clinical practice. Control Clin Trials. 1983;4:513-522.

3. Boissel JP. Impact of randomized clinical trials on medical practices. Control Clin Trials. 1989;10(suppl 4):120S-134S.

4. Fineberg HV. Clinical evaluation: how does it influence medical practice? Bull Cancer. 1987;74:333-346.

5. Combs JL, Cohen SM, Fine SL, Murphy RP, Patz A. The spectrum of senile macular degeneration (SMD) at the retinal vascular center. Presented at the 42nd Scientific Meeting of the Residents Association of the Wilmer Ophthalmological Institute; 1983; Baltimore, Md.

6. Finkelstein SN, Gilbert DL. Scientific Evidence and the Abandonment of Medical Technology: Study of Eight Drugs. Cambridge, Mass: Alfred P Sloan School of Management, Massachusetts Institute of Technology; 1983:1419-1483.

7. Lamas GA, Pfeffer MA, Hamm P, Wertheimer J, Rouleau JL, Braunwald E. Do the results of randomized clinical trials of cardiovascular drugs influence medical practice? N Engl J Med. 1992;327:241-247

8. Pfeffer MA, Braunwald E, Moye LA, et al. Effect of captopril on mortality and morbidity in patients with left ventricular dysfunction after myocardial infarction: results of the Survival and Ventricular Enlargement Trial. N Engl J Med. 1992;327:669-677.

9. Rouleau Ji, Moye LA, Pfeffer MA, et al. A comparison of management patterns after acute myocardial infarction in Canada and the United States. $N$ Engl J Med. 1993;328:779-784.

10. Ross-Degnan D, Soumerai SB, Fortess EF, Gurwitz JH. Examining product risk in context: market withdrawal of zomepirac as a case study. JAMA. 1993;270: 1937-1942.

11. Avorn J, Chen M, Hartley R. Scientific versus commercial sources of influence on the prescribing behavior of physicians. Am J Med. 1982;73:4-8.

12. Soumerai SB, Ross-Degnan D, Gortmaker S, Avorn J. Withdrawing payment for nonscientific drug therapy: intended and unintended effects of a largescale natural experiment. JAMA. 1990;263:831-839.

13. Soumerai SB, Avorn J, Ross-Degnan D, Gortmaker S. Payment restrictions for prescription drugs under Medicaid: effects on therapy, cost and equity. $N$ Engl J Med. 1987;317:550-556.

14. Soumerai SB, Ross-Degnan D, Kahn JS. Effects of professional media warnings about the association between aspirin use in children and Reye's syndrome. Milbank Q. 1992;70:155-182.

15. Stross JK, Bole GG. Evaluation of a continuing education program in rheumatoid arthritis. Arthritis Rheum. 1980;23:846-849.

16. Soumerai SB, McLaughlin TJ, Avorn J. Improving drug prescribing in primany care: a critical analysis of the experimental literature. Mibank $0.1989 ; 67: 268$ 317.

17. Soumerai SB, Ross-Degnan D, Fortess EE, Abelson J. A critical analysis of studies of state drug reimbursement policies: research in need of discipline. Mitbank Q. 1993;71:217-252.

18. Goldberg RJ, Gore JM, Alpert JS, Dalen JE. Recent changes in attack and sur- 
vival rates of acute myocardial infarction (1975 through 1981): the Worcester Heart Attack Study. JAMA. 1986;255:2774-2779.

19. Goldberg RJ, Gore JM, Alpert JS, Dalen JE. Incidence and case fatality rates of acute myocardial infarction (1975-1984): the Worcester Heart Attack Study. Am Heart J. 1988;115:761-767.

20. Goldberg RJ, Gorak EJ, Yarzebski J, et al. A community-wide perspective of sex differences and temporal trends in the incidence and survival rates after acute myocardial infarction and out-of-hospital deaths caused by coronary heart disease. Circulation. 1993;87:1947-1953.

21. Goldberg RJ, Gore JM, Alpert JS, Dalen JE. Therapeutic trends in the management of patients with acute myocardial infarction (1975-1984): The Worcester Heart Attack Study. Clin Cardiol. 1987;10:3-8.

22. Gore JM, Goldberg RJ, Alpert JS, Dalen JE. The increased use of diagnostic procedures in patients with acute myocardial infarction: a community-wide perspective. Arch Intern Med. 1987;147:1729-1732.

23. Goldberg RJ, Gore JM, Alpert JS, et al. Cardiogenic shock after acute myocardial infarction: incidence and mortality from a community-wide perspective, 1975 to 1988. N Engl J Med. 1991;325:1117-1122.

24. Soumerai SB, Avorn J, Ross-Degnan D, Gortmaker S. Payment restrictions for prescription drugs under medicaid: effects on therapy, cost, and equity. N Engl $J$ Med. 1987;317:550-556.

25. Soumerai SB, Ross-Degnan D, Gortmaker S, Avorn J. Withdrawing payment for nonscientific drug therapy: intended and unintended effects of a largescale natural experiment. JAMA. 1990;263:831-839.

26. Hosmer DW, Lemeshow S. Applied Logistic Regression. New York, NY: John Wiley \& Sons Inc; 1989.

27. Liang KY, Zeger SL. Longitudinal data analysis using generalized linear models. Biometrika. 1986;73:13-22.

28. Zeger SL, Liang KY, Albert PS. Models for longitudinal data: a generalized estimating equation approach. Biometrics. 1988;44:1049-1060.

29. Zeger SL, Liang KY. Longitudinal data analysis for discrete and continuous outcomes. Biometrics. 1986;42:121-130.

30. The American College of Cardiology and ISIS Collaborative Group. Results of a large randomised trial of intravenous streptokinase and oral aspirin in acute myocardial infarction. J Am Coll Cardiol. 1988;11:27A, 232A. Abstracts.

31. Second International Study of Infarct Survival (ISIS-2) Collaborative Group. Randomized trial of intravenous streptokinase, oral aspirin, both, or neither among 17,187 cases of suspected acute myocardial infarction: ISIS-2. Lancet. 1988;2:2349-2360.

32. Second International Study of Infarct Survival. Randomized trial of intravenous streptokinase, oral aspirin, both, or neither among 17,187 cases of suspected acute myocardial infarction: ISIS-2. J Am Coll Cardiol. 1988;12:(suppl A):3A-13A.

33. The Multicenter Diltiazem Postinfarction Trial Research Group. The effect of dittiazem on mortality and reinfarction after myocardial infarction. $N$ Eng/ $J$ Med. 1988;319:385-392.
34. The Israeli Sprint Study Group. Secondary Prevention Reinfarction Israeli Nifedipine Trial (SPRINT): a randomized intervention trial of nifedipine in patients with acute myocardial infarction. Eur Heart J. 1988;9:354-364.

35. International Study of Infarct Survival Collaborative Group. Results of a large randomized trial of intravenous streptokinase and oral aspirin in acute myocardial infarction. J Am Coll Cardiol. 1988;11:232. Abstract.

36. Moss AJ and the Multicenter Diltiazern Post-infarction Research Group. Longterm effect of diltiazem on mortality and reinfarction after myocardial infarction: the MDPIT Study. J Am Coll Cardiol. 1988;11:27. Abstract.

37. Elwood PC, Cochrane AL, Burr ML, et al. A randomized controlled trial of acetylsalicylic acid in the secondary prevention of mortality from myocardial infarction. BMJ. 1974;1:436-440.

38. The Coronary Drug Project Research Group. Aspirin in coronary heart disease $J$ Chronic Dis. 1976;29:625-642.

39. Elwood PC, Sweetnam PM,. Aspirin and secondary mortality after myocardial infarction. Lancet. 1979;2:1313-1315.

40. The Persantine-Aspirin Reinfarction Study Research Group. Persantine and aspirin in coronary heart disease. Circulation. 1980;62:449-461.

41. Breddin K, Loew D, Lechner K, Uberla K, Walter E. Secondary prevention of myocardial infarction: a comparison of acetyl-salicylic acid, placebo, and phenprocoumon. Haemostasis. 1980;9:325-344.

42. Elwood PC. British studies of aspirin and myocardial infarction. Am J Med. 1983;7:50-54.

43. International Study of Infarct Survival Pilot Study Investigators. Randomized factorial trial of high dose intravenous streptokinase, of oral aspirin and of intravenous heparin in acute myocardial infarction. Eur Heart J. 1987;8:634642.

44. Gurwitz JH, Col NF, Avorn J. The exclusion of the elderly and women from clinical trials in acute myocardial infarction. JAMA. 1992;268:1417-1422.

45. Friedman L, Wenger NK, Knatterud GL. Impact of the coronary drug project findings on clinical practice. Control Clin Trials. 1983;4:513-522.

46. Becker MH. Factors affecting diffusion of innovations among health professionals. Am J Public Health. 1970;60:294-304.

47. Rogers EM. Diffusion of Innovations. New York, NY: The Free Press; 1983:186.

48. Coleman JS, Katz E, Menzel H. Medical Innovation: A Diffusion Study. Indianapolis, Ind: Bobbs-Merrill; 1966.

49. Ketley D, Woods KL. Impact of clinical trials on clinical practice: example of thrombolysis for acute myocardial infarction. Lancet. 1993;342:891-894.

50. US Congress Office of Technology Assessment. The Impact of Randomized Clinical Trials on Health Policy and Medical Practice. Washington, DC: US Government Printing Office; 1983. Office of Technology Assessment publication BP-H-22.

51. Bunker JP, Barnes BA, Mosteller F, eds. Progress in surgery and anesthesia: benefits and risks of innovative therapy. In: Costs, Risks, and Benefits of Surgery. New York, NY: Oxford University Press Inc; 1977:124. 